\title{
Candidates for multiple impact craters?: Popigai and Chicxulub as seen by the global high resolution gravitational field model EGM2008
}

\author{
J. Klokočník ${ }^{1}$, J. Kostelecký $\hat{y}^{2,3}$, I. Pešek ${ }^{3}$, P. Novák ${ }^{2,4}$, C. A. Wagner ${ }^{5}$, and J. Sebera ${ }^{1,3}$ \\ ${ }^{1}$ Astronomical Institute, Academy of Sciences of the Czech Republic, Ondřejov, Czech Republic \\ ${ }^{2}$ Research Institute for Geodesy, Topography and Cartography, Zdiby, Czech Republic \\ ${ }^{3}$ Department of Advanced Geodesy, Czech Technical University, Prague, Czech Republic \\ ${ }^{4}$ Department of Math., Faculty of Applied Sciences, University of West Bohemia, Pilsen, Czech Republic \\ ${ }^{5}$ Laboratory for Satellite Altimetry, NOAA, Silver Spring, MD, USA
}

Received: 15 January 2010 - Published in Solid Earth Discuss.: 9 March 2010

Revised: 22 June 2010 - Accepted: 12 July 2010 - Published: 21 July 2010

\begin{abstract}
In 2008 the new Earth Gravitational Model (EGM2008) was released. It contains a complete set of spherical harmonic coefficients of the Earth's gravitational potential (Stokes parameters) to degree 2190 and order 2159 and selected orders to degree 2190 , that can be used for evaluation of various potential quantities with both the unprecedented accuracy and high spatial resolution. Two such quantities, the gravity anomaly and second-order radial derivative of the disturbing potential, were computed over selected areas with known impact craters. The displays of these derivatives for two such sites clearly show not only the strong circular-like features known to be associated with them but also other symmetrical structures which appear to make them multiple impact sites. At Popigai, Siberia, the series of circular features fall in a line from the "primary crater" in the southeast (SE) direction. At Chicxulub, Yucatán, there appears to be one more crater close to the "primary" in the northeast (NE) direction, as well as possibly others in the vicinity of the main crater (SW). Gravity information alone is not, however, proof of impact craters but it is useful in identifying candidate sites for further study, for examination by geologists and geophysicists. In the case of Chicxulub, a very recent single seismic profile suggests that a more likely explanation for the observed circular like gravity signal from EGM2008 NE of the "primary" is a pre-impact basin.
\end{abstract}

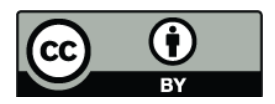

Correspondence to: J. Klokočník (jklokocn@asu.cas.cz)

\section{Introduction}

There are about 175 currently known impact meteoritic craters on the Earth's surface (see Earth Impact Database 2006, EID - www.unb.ca/passc/ImpactDatabase) and an impact origin for over 600 additional structures has been proposed (Rajmon, 2009). We computed the gravity anomaly and second-order radial derivative of the disturbing gravitational potential at about 30 of the confirmed larger impact crater sites (from EID), and at some other promising places (also from the list of Rajmon, ibid). Here we give two examples of what appears to be double or multiple impact craters at two of those well known locations, namely Popigai in Siberia, Russia, and Chicxulub in North Yucatán, México; for more details and examples see the preparatory study Klokočník et al. (2008a) and (www.asu.cas.cz/ jklokocn].

The novelty of our approach is in: (1) we use a very detailed Earth Gravitational Model EGM2008 (Pavlis et al., 2008 a,b) with theoretical resolution $5^{\prime} \times 5^{\prime}$ (arcminutes) or $9 \times 9 \mathrm{~km}$ on the ground, and (2) we computed and analysed two functionals of the disturbing potential, namely the gravity anomaly $\Delta g\left(1 \mathrm{mGal}=10^{-5} \mathrm{~m} \mathrm{~s}^{-2}\right)$ and the second-order radial derivative $T_{\text {rr }}$ (Eõtvõs, $1 \mathrm{E}=10^{-9} \mathrm{~s}^{-2}$ ). Note that the latter quantity was available only as numerical derivatives from measured gravity, e.g., Evjen (1936) or Elkins (1951).

The circular like gravitational signals alone are not proof of an impact origin, they are just one indication. Additional data are needed to confirm an impact origin, such as magnetic anomalies, seismic profiles or deposits of shockmetamorphic minerals, etc. Nevertheless, gravity data together with other geophysical data can establish general criteria that correspond to the geophysical signature of impact

Published by Copernicus Publications on behalf of the European Geosciences Union. 
craters (Pilkington and Grieve, 1992; French and Koeberl, 2010). Final confirmation of an impact origin needs the geologic evidence. For the two cases considered here, the presence of additional circular structures close to the "primaries" which are known as impact craters, strongly suggests that these "companions" are also of impact origin (but see the continuation, namely Sect. 5).

It is useful to recall the history of the discovery of the Chicxulub or Mjølnir impact craters, where the gravity data played an important role in a first phase of study; such data were and are important for identifying anomalous structures for future examination. It is true that the discovery of gravity and magnetic anomalies associated with suspected structures have led directly to their confirmation as impact structures (e.g., Pilkington and Grieve, 1992; see details in the recent review paper French and Koeberl, 2010). We do not see the geological verification as a part of our role; we had a desire to jump-start geological and geophysical investigations by others (see Sect. 5).

For a double crater one scenario could be an impact from a binary asteroid. A binary asteroid can be generated by repeated close encounters with the Earth. It is estimated and observed that $15 \pm 4 \%$ of the population of near-Earth asteroids larger than $200 \mathrm{~m}$ in diameter, are binaries (see Sect. 4.5.). In addition a part of multiple craters might form from the asteroid's breakup in the Earth's atmosphere.

\section{Data and formulae}

\subsection{EGM2008 gravitational field model}

EGM2008 is a current highly detailed Earth Gravitational Model (Pavlis et al., 2008a) that contains numerical geopotential coefficients $C_{\mathrm{n}, \mathrm{m}}$ and $S_{\mathrm{n}, \mathrm{m}}$ of a spherical harmonic expansion complete to degree and order 2159 with additional coefficients complete to degree 2190 but no order higher than 2159. In addition to the satellite data from the mission GRACE (Gravity Recovery and Climate Experiment, NASA satellite active since 2002, see, e.g., www.nasa. gov/missions/, www.csr.utexas.edu/grace/, op.gfz-potsdam. de/grace/satellite/ and many more), the model was computed by using $5^{\prime} \times 5^{\prime}$ area mean free-air gravity anomalies $\Delta g$ derived from ground gravity surveys and satellite altimetry both compiled nearly worldwide by the US National GeospatialIntelligence Agency (NGA).

The precision of EGM2008 gravity anomaly computations for Popigai or Yucatan and many other places, expressed in terms of its commission error, is at the level of a few miliGals (Fig. 1). But in some localities the precision is worse and can be $\sim 30 \mathrm{mGal}$, together with much lower resolution, e.g., in Antarctica (because only the GRACE data were used there). This information is used below for the accuracy assessments. We will see for example that the maximum Signal to Noise ratio $(S / N)$ for gravity anomalies at Popigai or

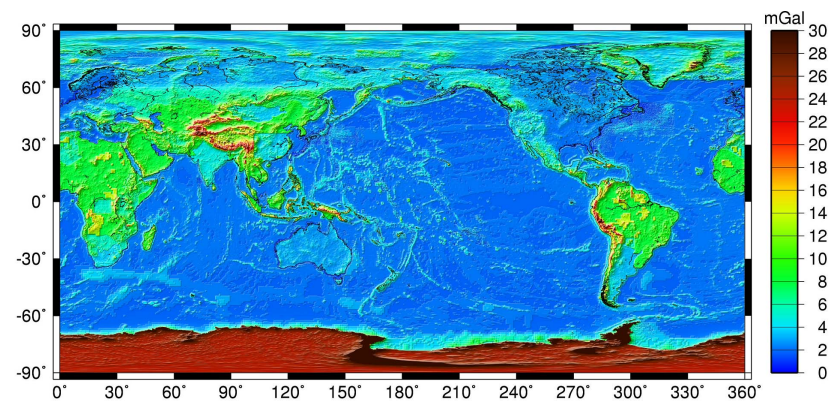

Fig. 1. The commision error of gravity anomalies of EGM2008 (reproduced from Pavlis et al., 2008a) or standard deviation of free air spherical approximation of the gravity anomalies. Scale in miligals [mGal].

Chicxulub is about 30, (from Fig. 1), inevitably smaller for the second derivatives but still large enough in both cases to confirm the additional circular-like features as real and not artifacts (see Sect. 4.2.).

For our use we will define and compute $R=S / N$ (to eliminate zero $S$ cases) as follows

$\min R=(\min (\max |-S|, \max +S)) /(\max N)$,

$\max R=(\max (\max |-S|, \max +S)) /(\min N)$

for the gravity anomalies and second radial derivatives in the areas of interest, i.e. $\Omega\left(\phi_{\min }, \lambda_{\min }, \phi_{\max }, \lambda_{\max }\right)$, where $(\phi$, $\lambda)$ are geographic latitude and longitude of the center of the area of interest.

Using Figs. 1 (defining $N$ ) and 2, 4 (defining $S$ ) for Popigai and Chicxulub (the extent of the areas is visible below on Figs. $2-5)$, we get $R(\min , \max )=8-15$ for Popigai and 5-20 for Chicxulub. Statistically, the required minimum $R=3$.

It should be fully appreciated by geologists how important progress is represented by the EGM2008 as for the accuracy, resolution and homogeneity of its gravity field description (Pavlis et al., 2008a,b). Without EGM2008, our analyses would be impossible (Klokočník et al., 2008a,b).

\subsection{Formulae}

The following quantities, functionals of the Earth's gravitational potential expressed by EGM2008, can actually be computed for our purposes by using software for spherical harmonic synthesis (Holmes et al., 2006):

(1) free-air gravity anomaly, more precisely "spherically approximated gravity anomaly", $\Delta g=-\partial \mathrm{T} / \partial r-2 T / r$, where $T$ is the disturbing gravitational potential $T=V-U$ with the normal potential $U$ represented by the Geodetic Reference System 1980 (GRS 80, Moritz 1984);

(2) second-order derivatives of $T$ on the main diagonal of the Marussi tensor, i.e. $T_{\mathrm{xx}}, T_{\mathrm{yy}}$ and $T_{\mathrm{zz}}$ in the local oriented coordinate frame, namely the second radial 
derivative $T_{\mathrm{zz}} \approx T_{\mathrm{rr}}=\partial^{2} T / \partial r^{2}$, where $r$ is the geocentric radius of a general computation point.

All model computations were evaluated at the surface of the reference ellipsoid (GRS 80) on a grid of ellipsoidal coordinates with equiangular spacing of $5^{\prime}$.

The gravity anomaly is defined through the fundamental gravimetric equation that reads in spherical approximation:

$\Delta g(r, \theta, \lambda)=-\left(\frac{\partial}{\partial r}+\frac{2}{r}\right) T(r, \theta, \lambda)$

$=\frac{\mathrm{GM}}{a_{\mathrm{e}}^{2}} \sum_{n=2}^{2190}(n-1)\left(\frac{a_{\mathrm{e}}}{r}\right)^{n+2} T_{\mathrm{n}}(\theta, \lambda)$

where $a_{\mathrm{e}}$ is the scaling factor of EGM2008 (the Earth's mean equatorial radius), and the surface spherical harmonic functions are

$T_{\mathrm{n}}(\theta, \lambda)=\sum_{m=0}^{\mathrm{n}}\left(C_{\mathrm{n}, \mathrm{m}} \cos m \lambda+S_{\mathrm{n}, \mathrm{m}} \sin m \lambda\right) P_{\mathrm{n}, \mathrm{m}}(\cos \theta)$.

Here, $P_{\mathrm{n}, \mathrm{m}}$ are associated Legendre functions of the first kind, $n$ is degree and $m$ order of the harmonic expansion and $\theta, \lambda$ represent spherical co-latitude and longitude. We still use $\Delta g$ (and not for example the radial gravity disturbances, i.e., the first-order radial derivative of the potential) because sometimes traditional local ground gravity data in the form of $\Delta g$ (free air or Bouguer's type) are available and might be used for a comparison.

The second-order radial derivative of the disturbing gravitational potential in the spherical approximation is

$T_{\mathrm{rr}}(r, \theta, \lambda)=\frac{\partial^{2}}{\partial r^{2}} T(r, \theta, \lambda)$

$=\frac{\mathrm{GM}}{a_{\mathrm{e}}^{3}} \sum_{n=2}^{2190}(n-1)(n+2)\left(\frac{a_{\mathrm{e}}}{r}\right)^{n+3} T_{\mathrm{n}}(\theta, \lambda)$.

\section{Preliminary analysis}

\subsection{Popigai - a multiple crater?}

Popigai $\left(\phi=71^{\circ} 39^{\prime} \mathrm{N}, \lambda=111^{\circ} 11^{\prime} \mathrm{E}\right)$ is a very large impact structure (diameter of about $100 \mathrm{~km}$, age $36 \mathrm{My}$ ) located at the Anabar shield, central Arctic Siberia, near the seashore. The main crater at Popigai is partly visible on the surface. The shock pressures from the impact instantaneously transformed graphite in the ground into diamonds near the central zone of the crater (Masaitis, 1998). Coesite and stishovite (strongly indicating an impact origin) are also present there (see Pilkington et al., 2002 for additional references).

Figures 2 and 3 show $\Delta g$ and $T_{\text {rr }}$ for the Popigai area. We think EGM2008 clearly reveals more than one crater, lined up close to the original (visible crater) at Popigai in the NWSE direction. We label these structures Popigai I, II, III, (and
IV?). Our hypothesis is that the Popigai structure is a multiple crater.

A simple geological map of Popigai is available but only for the "primary" crater "Popigai I" (Pilkington et al., 2002). We have not seen the original terrestrial gravity anomalies (they appear to be "proprietary" of soviet/Russian authorities) but they were evidently used by NGA for EGM2008 (no comment in Pavlis et al., 2008 a,b).

\subsection{Chicxulub - a double crater?}

The Chicxulub structure in the North Yucatán Peninsula, México $\left(\phi=21^{\circ} 20^{\prime} \mathrm{N}, \lambda=2706 \circ 30^{\prime} \mathrm{E}\right)$ is a multi-ringed impact crater buried partly under a flat surface and partly under a shallow sea (it is not visible on the surface). The crater was discovered (in the late 1970s) with the aid of the ground gravity and magnetic anomalies (collected by the oil company Petróleos Mexicanos, and others), disclosing concentric, ring-like patterns. This structure is also marked by shock-metamorphosed minerals, sinkholes (cenotes) and a number of seismic profiles revealing its circular nature below ground (e.g., Surendra, 2004).

The size of the crater has been discussed intensively. Earlier investigations (e.g., Hildebrand et al., 1995, 1998) found that there were two rings with the diameters of about 80 and $170 \mathrm{~km}$, although others (e.g., Sharpton et al., 1993) identified two more-distant rings in their gravity profiles, and interpreted a $300 \mathrm{~km}$ wide crater. The analysis of Espindola et al. (1995) did not support more rings. From the most recent papers we recommend Vermeesch and Morgan (2008) and the review with many references (French and Koebert, 2010).

Bottke et al. (2007) discovered that Chicxulub is a result of an impact of a fragment (of carbonaceous chondrite) from the Baptistina asteroid family, the first such specific identification of an origin among Earth impactors.

One of the older global Earth's gravitational models, EGM96 (Lemoine et al., 1998), providing $50 \mathrm{~km}$ half wavelength resolution, showed a negative gravity anomaly in the Chicxulub area, but revealed no further details. Newer gravitational models computed with the help of data solely from the recent gravity dedicated satellite missions CHAMP (CHAllenging Minisatellite Payload for geoscience and application) and GRACE (see above) unfortunately did not reveal many more details (Klokočník et al., 2008a and www. asu.cas.cz/ jklokocn), due to their lower spatial resolution ( $\sim 150 \mathrm{~km})$.

Figures 4 and 5 show $\Delta g$ and $T_{\mathrm{rr}}$ for the Chicxulub area when the complete EGM2008 model is employed. Two circular-like but fragmented structures (about a common center) are clearly visible with negative values of $T_{\mathrm{rr}}$, which also includes two central positive parts, and two fragmented rings with positive anomalies. The outer ring has the diameter $160-180 \mathrm{~km}$. Outer "circles" of minimum and maximum 


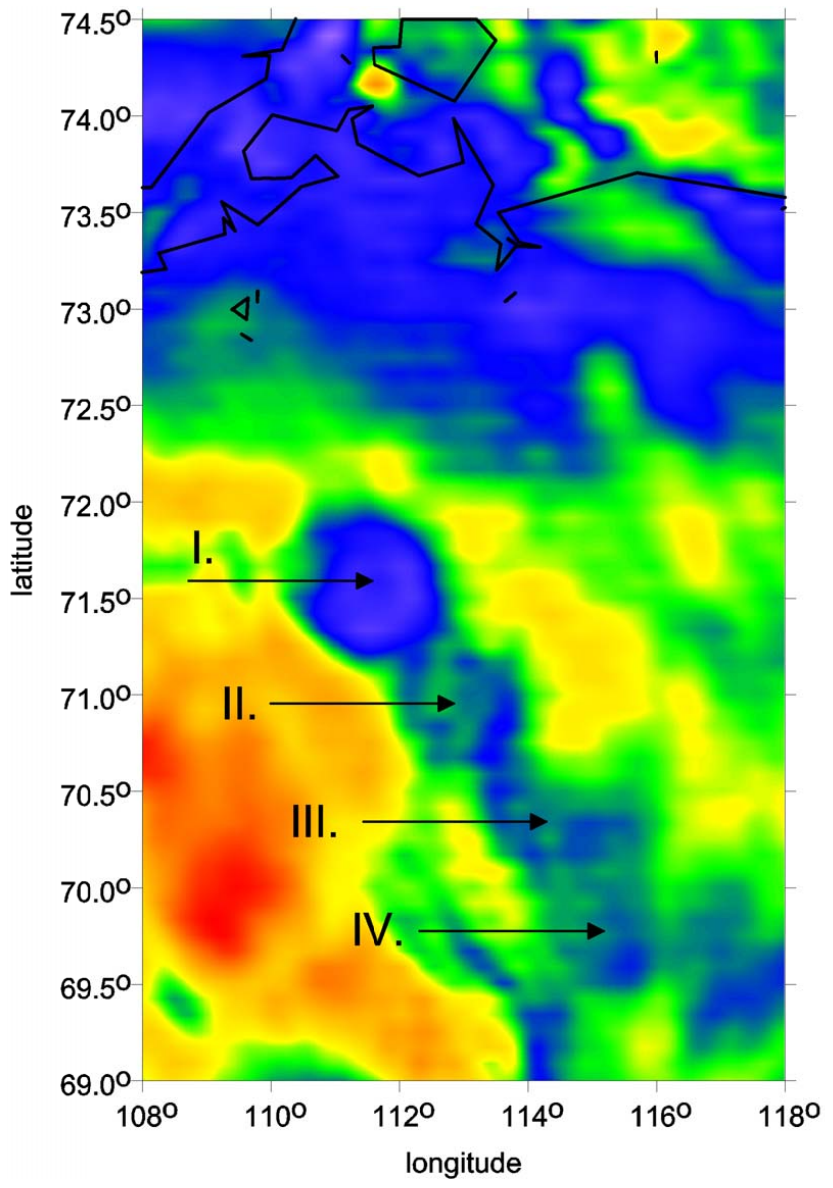

Fig. 2. Gravity anomalies $\Delta g$ [mGal] computed from the complete EGM2008 at Popigai, Siberia, Russia. Here and everywhere (excluding Figs. 10, 11 and 12) there is a nonlinear scale with green color at zero. The arrows point to Popigai I, II, II (and IV).

gradients with a possible diameter $\sim 250 \mathrm{~km}$ are uncertain being faint and very fragmented.

Moreover, in the NE direction from the Chicxulub impact, we can see a less pronounced circular-like feature (Figs. 4 and 5), partly interfering with the outer ring of the original Chicxulub. This smaller crater-like feature seems to have two rings with the diameter for the outer ring of about $100 \mathrm{~km}$. It is fair to note that the existence of the second crater might have been anticipated (but was not) already from older maps of the ground gravity anomalies, see Fig. $2 b$ in Sharpton et al. (1993) or Fig. 1 in Hildebrandt et al. (2003). We will test the hypothesis that Chicxulub is a double (if not a multiple) crater (Sects. 4 and 5).

\section{Further analysis}

It is not enough to compute $\Delta g$ and $T_{\text {rr }}$, identifying circular structures and to claim that we have new candidates for impact craters. We wish to provide additional evidence. We

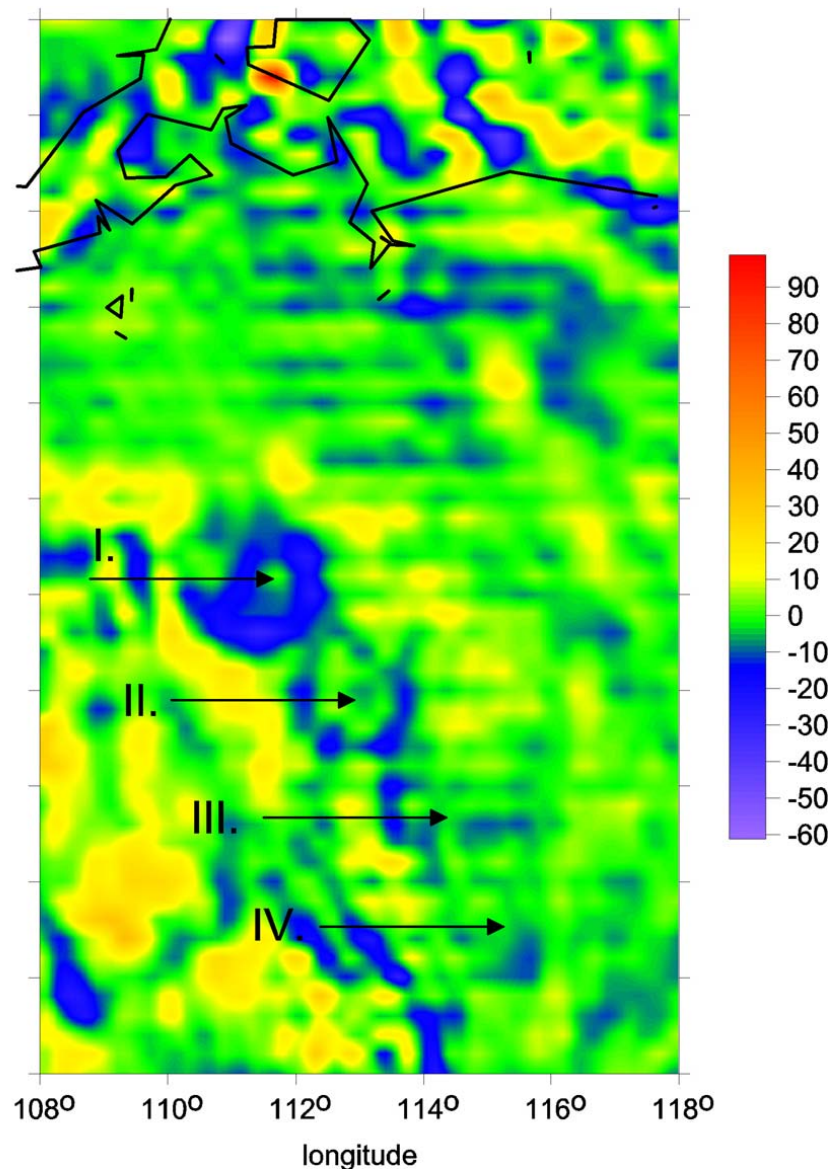

Fig. 3. Second radial derivative $T_{\mathrm{rr}}[\mathrm{E}]$ computed from the complete EGM2008 at Popigai (note circular-like candidates for impact craters less pronounced than the original crater but visible in the SE direction from the original one).

found many examples with EGM2008 of circular-like gravity signals due to volcanoes and other known tectonic structures. We can distinguish them from the signal of a possible impact structure (Klokočník et al., 2008a); in these assessments we always cooperated with geologists. We also detected various artifacts namely in $T_{\text {rr }}$ due probably to aliasing in the EGM2008 solution, and we are also able to distinguish them from the craters (ibid).

To support the interpretation of our initial survey of Chicxulub and Popigai, here we show comparisons with the DNSC08 database (Andersen et al., 2008), accuracy estimates, filtering of $T_{\mathrm{rr}}$, and examples of crater modeling.

\subsection{Comparison with the DNSC08 database, with Russian data for Popigai and terrestrial gravity anomalies for Chicxulub}

The DNSC08 database contains sea surface heights from global altimetry (Andersen et al., 2008). The Danish National Space Center (DNSC) 08 gravitational model uses the 


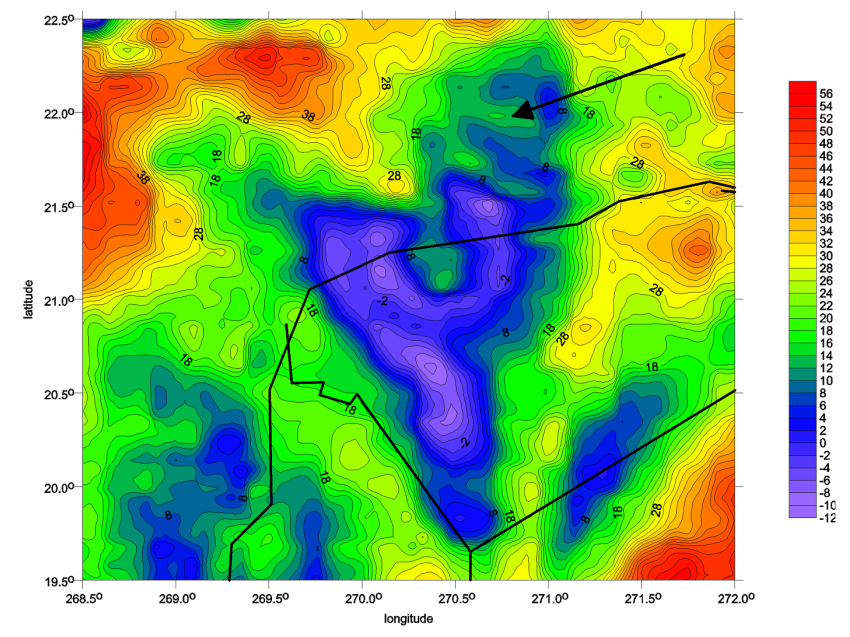

Fig. 4. Gravity anomalies $\Delta g$ [mGal] based on the complete EGM2008 at Chicxulub (the arrow indicates a possible companion crater).

same surface gravity anomaly source as EGM2008 but at higher resolution $\left(2^{\prime} \times 2^{\prime}\right)$. Although the two models are not independent, a comparison is useful.

We show examples for Popigai in Fig. 6c and d; the greater detail in DNSC08 is even more convincing for a multiple crater. The situation is very similar for Chicxulub, see Fig. 7a and $b$, with interesting details for the location of the candidate for Chicxulub II.

For Popigai, we also reproduce here results from the older soviet gravity data, taken from Fig. 3a of Pilkington et al. (2002), which we have unfortunately in the form of the figures only, see Fig. 6a,b. We can see that the negative gravity anomaly of Popigai I (Fig. 6a) is extended in the southeast for the candidate crater Popigai II. We note that the filtering of the anomalies to retain wavelength components $<50 \mathrm{~km}$ indicates two circular structures at places which we expect for Popigai I and II. This looks promising and supports our hypothesis; compare to Fig. 5 in Masaitis et al. (2005).

The terrestrial gravity anomalies used by Hildebrand et al. (1995), kindly provided by Dr. M. Pilkington, are shown in Fig. 7c (in GPU units, $1 \mathrm{GPU}=10 \mathrm{~m}^{2} \mathrm{~s}^{-2}$ ) for Chicxulub and should be compared with Fig. 7a and b. Figure 7c discloses clearly that EGM2008 made use of very similar terrestrial data sets as those of the earlier investigators. The agreement between EGM2008 and Pilkington's data in particular is very good on land.

\subsection{Input data accuracy assessments}

An accuracy assessment for the computed $\Delta g$ and $T_{\mathrm{rr}}$ is not easily obtained since a covariance matrix is only available for the low degree portion of the EGM2008 field and integral formulas must be used for the vast number of higher degree terms (Pavlis and Saleh, 2005). This approach, leading to

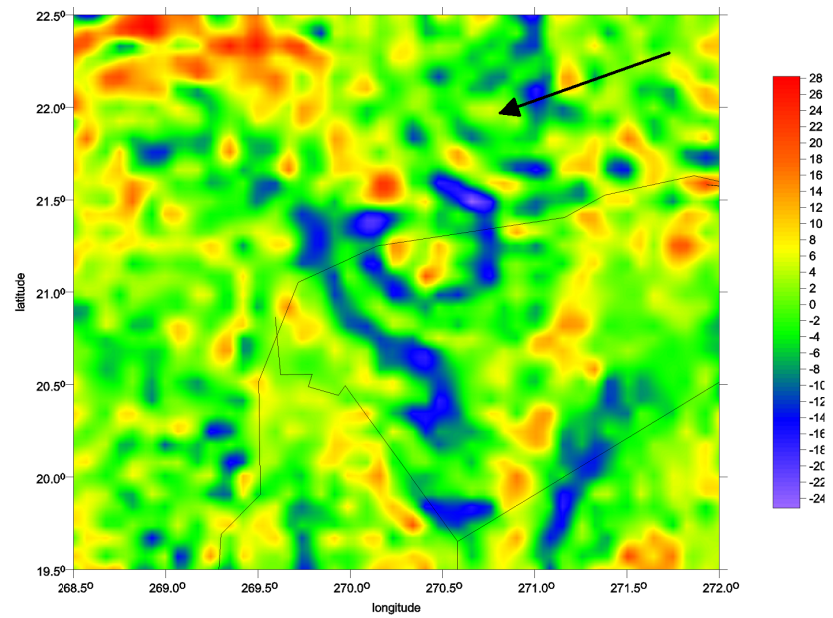

Fig. 5. Second derivatives $T_{\mathrm{rr}}$ based on the complete EGM2008 at Chixculub [E]. To be compared also with Fig. 4 in Espindola et al. (1995).

the commission error mentioned above (displayed in detail in Fig. 1), was globally evaluated for the gravity anomaly, geoid undulation and deflections of the vertical in EGM2008 (Pavlis et al., 2008a,b).

In the vicinity of these impact structures, do the signals (in $\Delta g$ and $T_{\mathrm{rr}}$ and their changes $(\operatorname{grad}(\Delta g))$ and $\left.\operatorname{grad}\left(T_{\mathrm{rr}}\right)\right)$ stand out above their estimated precision? For the gravity anomaly we could use directly the commission error offered by the authors of EGM2008 (Fig. 1), while the commission error for the second radial derivative should be somehow estimated. We already know that $\Delta g$ for Popigai and Chicxulub are robust signals (Figs. 2 and 4) compared to their commission errors (Fig. 1). How do we estimate the errors of the gradient signals?

For this purpose we used the commission error of deflections of the vertical. Firstly, $T_{\mathrm{rr}}$ as a function of deflections of the vertical and some further simplification is needed. We can obtain such a relation by differentiating the basic equation of physical geodesy Eq. (2) in its spherical approximation (Hofmann-Wellenhof and Moritz, 2003, p. 121), which leads to:

$\frac{\partial \Delta g}{\partial r}=-\frac{\partial^{2} T}{\partial r^{2}}-\frac{2}{r} \frac{\partial T}{\partial r}+\frac{2}{r^{2}} T$.

where all symbols were explained above. Equation (4) connects the radial derivative of the gravity anomaly with the second radial derivative of the disturbing potential. One could find out by numerical evaluation that both quantities are very close to each other. An agreement was checked in terms of the RMS for both localities. For Popigai, it was found: $\operatorname{RMS}\left|\frac{\partial \Delta g}{\partial r}-\frac{\partial^{2} T}{\partial r^{2}}\right|=0.071 \mathrm{E}$, while for Chicxulub: RMS $\left|\frac{\partial \Delta g}{\partial r}-\frac{\partial^{2} T}{\partial r^{2}}\right|=0.067 \mathrm{E}$, which warrants our setting $\frac{\partial \Delta g}{\partial r} \approx-\frac{\partial^{2} T}{\partial r^{2}}$ precise enough for the accuracy assessments. 

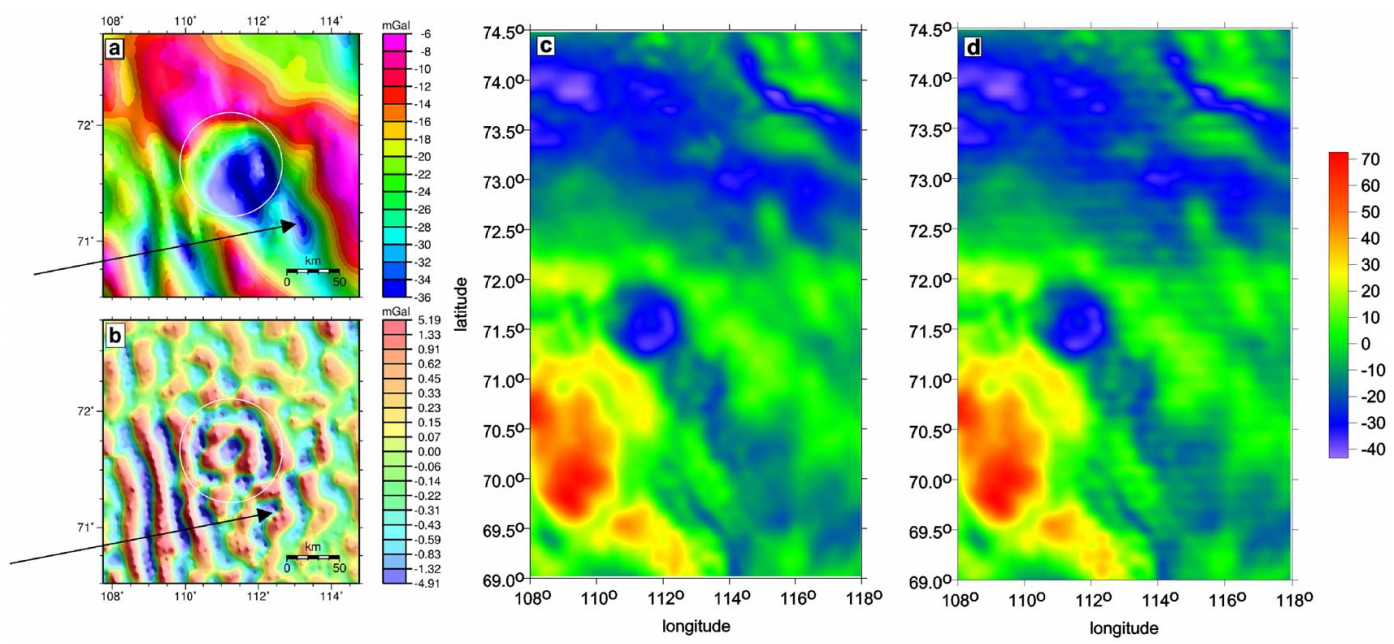

Fig. 6. Gravity anomalies (Bouguer's) over the Popigai region (data courtesy GETECH Ltd); reproduced from Fig. 3a of Pilkington et al. (2002), here panel (a). White circles represent estimated crater at $100 \mathrm{~km}$ diameter. The high-pass filtered gravity anomalies to retain wavelength component $<50 \mathrm{~km}$, panel (b). The arrows show locations of possible impact crater Popigai II. Gravity anomalies computed with DNSC08, resolution $2 \times 2^{\prime}$, panel (c), as compared to those with EGM2008, resolution $5 \times 5^{\prime}-$ panel (d), see also Fig. 2).

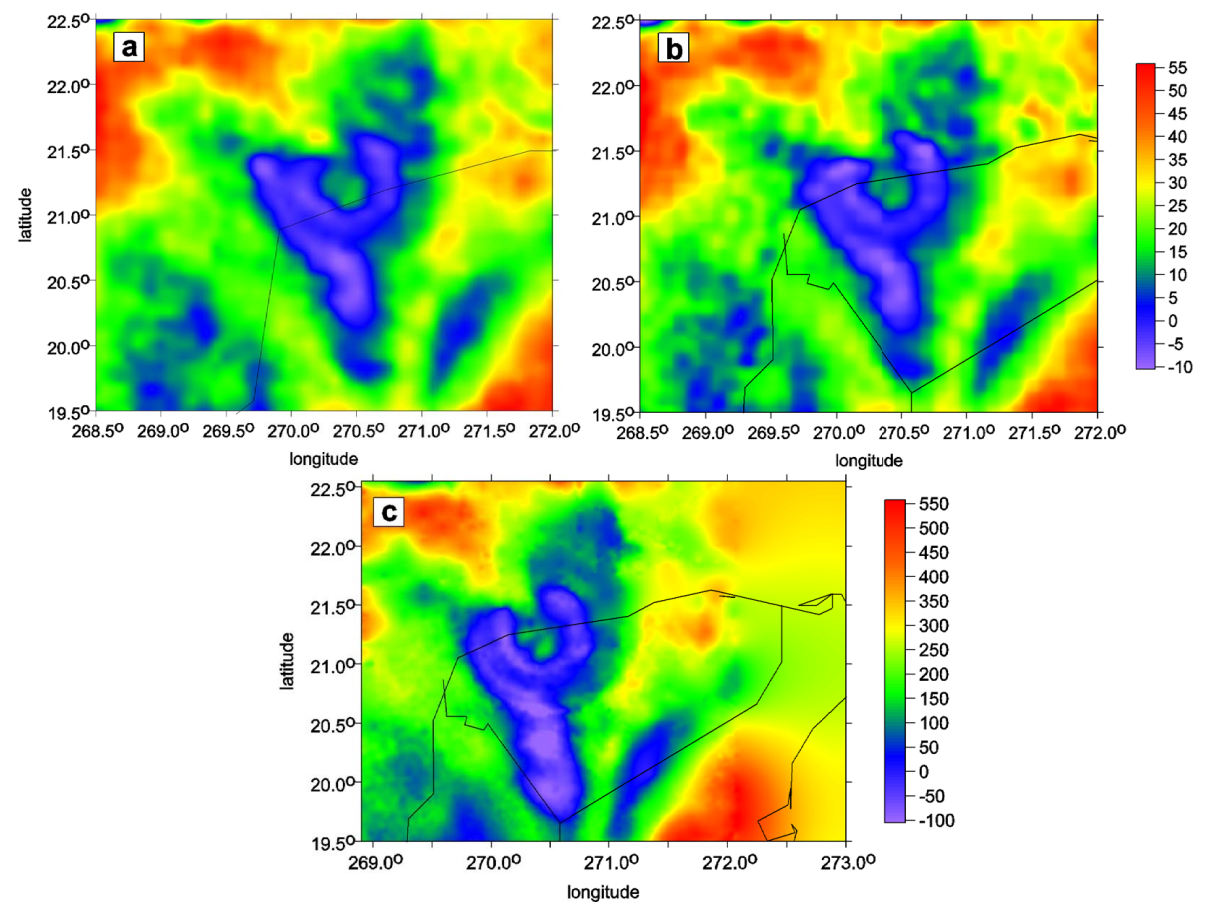

Fig. 7. Chicxulub, Yucatán. Gravity anomalies computed with DNSC08, resolution $2 \times 2$ (a) as compared to those with EGM2008, resolution $5 \times 5^{\prime}$ (b). Terrestrial gravity anomalies as used, e.g., by Hildebrand et al. (1995), (c). To be compared to panels (a) and (b); in panel (c) the units are "g u" or "GPU" (geopotential units), 1 GPU $=10 \mathrm{~m}^{2} \mathrm{~s}^{-2}$.

Considering this strong correlation we may use $\frac{\partial \Delta g}{\partial r}$ as a function of the deflections of the vertical for the accuracy assessment of $T_{\text {rr }}$. From (ibid, p. 122), the quantity $\frac{\partial \Delta g}{\partial r}$ can be written as follows:

$$
\frac{\partial \Delta g}{\partial r}=-\gamma_{0}\left(\frac{\partial \xi}{\partial x}+\frac{\partial \eta}{\partial y}\right)
$$

where $\xi$ means the north-south component (direction in $x$ axis) and $\eta$ denotes the east-west component of the deflection of the vertical (direction in $y$ axis) and $\gamma_{0}$ is the normal gravity acceleration $\left(\sim 10 \mathrm{~m} / \mathrm{s}^{2}\right)$. The commission error of $T_{\text {rr }}$ can be approximated via error propagation based on the 
Table 1. Range of $\Delta g$, grad $(\Delta g)$ and its estimated errors for the Chicxulub and Popigai areas.

\begin{tabular}{lcccl}
\hline Area & $\Delta \mathrm{g}[\mathrm{mGal}]$ & $\sigma(\Delta g)[\mathrm{mGal}]$ & $\operatorname{grad}(\Delta g)[\mathrm{mGal}]$ & $\sigma(\operatorname{grad}(\Delta g))[\mathrm{mGal}]$ \\
\hline Chicxulub & -20 to +60 & 2 to 7 & -18 to +13 & 1.5 to 4.5 \\
Popigai & -40 to +65 & 2 to 5 & -20 to +20 & 1.8 to 3
\end{tabular}

Table 2. Range of $T_{\mathrm{rr}}$, $\operatorname{grad}\left(T_{\mathrm{rr}}\right)$ and its estimated errors according to Eq. (6) for the Chicxulub and Popigai areas.

\begin{tabular}{lrrrl}
\hline Area & $T_{\text {rr }}[\mathrm{E}]$ & $\sigma\left(T_{\text {rr }}\right)[\mathrm{E}]$ & $\operatorname{grad}\left(T_{\text {rr }}\right)[\mathrm{E}]$ & $\sigma\left(\operatorname{grad}\left(T_{\text {rr }}\right)\right)[\mathrm{mGal}]$ \\
\hline Chicxulub & -30 to +40 & 4 to 9 & -18 to +15 & 2.5 to 5.5 \\
Popigai & -35 to 30 & 10 to 14 & -25 to 30 & 4 to 10 \\
\hline
\end{tabular}

deflection of the vertical's commission error as follows:

$\sigma^{2}\left(T_{\mathrm{rr}}\right) \approx \sigma^{2}\left(\frac{\partial \Delta g}{\partial r}\right) \approx \gamma_{0}^{2}\left[\sigma^{2}\left(\frac{\partial \xi}{\partial x}\right)+\sigma^{2}\left(\frac{\partial \eta}{\partial y}\right)\right]$,

where the relevant covariances are neglected, being unknown in EGM2008.

The comparison was performed for Chicxulub (see Fig. 8a,b) and Popigai (Fig. 9a,b). Table 1 yields a summary from Figs. 8a and 9a for the gravity anomalies, where we compare $\Delta g$ - or $\operatorname{grad}(\Delta g)$ - with the corresponding error estimation. Since the "signal" $\Delta g$ or $T_{\mathrm{zz}}$ oscillates around zero, we cannot use the $S / N$ ratio directly, but the range of both signal and noise suffices to judge the signal's reliability. We will use $R$ (min,max), defined by Eq. (1) from Sect. 1.

We see from Table 1 that $R(\min , \max )$ is $3-12$ for Chicxulub and 7-11 for Popigai (in fair agreement with estimates from Sect. 1).

Similarly Table 2 summarizes the range of signal $T_{\mathrm{rr}}-$ or $\operatorname{grad}\left(T_{\mathrm{rr}}\right)-$ with respect to its estimated error based on Figs. $8 \mathrm{~b}$ and $9 \mathrm{~b}$. Here, $R(\min , \max )$ is 3 and 7 for the both areas.

So even the second radial derivative $T_{\text {rr }}$ yields usually a good proportion between signal and noise, sufficient enough to use EGM2008 for our "impact prospecting". It is necessary to recall, however, that such assessments are - due to some assumptions (see Eq. 6) - a rough estimate only rather than a correctly done error propagation (Pavlis and Saleh, 2005).

\subsection{Filtering the second-order radial derivative}

This attempt deals with filtering (removing) of longwavelength features in $\Delta \mathrm{g}$ and $T_{\mathrm{rr}}$ with the goal to support our hypothesis about double/multiple impact craters. We computed $T_{\text {rr }}$ again but without terms up to degree and order 36 and 360 respectively, leaving only the higher degree/order part as it is in EGM2008, see Fig. 10a,b. The question is what will remain from the original circular-like features shown in Figs. 2 and 3? We show here the examples for Popigai. We see that the circular-like features "survived" this filtering. We have no proof but a new, additional indication supporting our hypothesis.

\subsection{Crater modeling}

\subsubsection{Method}

To provide an independent check of our previous findings of the new candidates for impact craters, we tried to model these putative objects by a point masses model, using accessible geological data as constraints. We compared gravity anomalies from these models with those from EGM2008. In both cases (Chicxulub and Popigai), the hypothetic companion looks like a "twin" of the "primary" crater.

Gravity anomalies, $\Delta g$, and the second radial derivatives, $T_{\mathrm{rr}}$, are obtained by numerical integration over the crater body using the formulas

$$
\begin{aligned}
& \Delta g=f \int_{\tau} \sigma r^{-2} \cos z d \tau+E, \\
& T_{\mathrm{rr}}=f \int_{\tau} \sigma r^{-3}(3 \sin 2 z-1) d \tau+E^{\prime}
\end{aligned}
$$

where $f$ is the gravitational constant, $\sigma$ density anomaly relative to the crater surroundings, and $r, z$ are the distance and the zenith distance to the mass element $d \tau$, respectively. The constants $E$ and $E^{\prime}$ shift the integrated values to fit numerically to the EGM2008 data.

It is evident that this task is not unique since various mass distributions can produce the same gravity anomalies. To avoid mistakes, we always followed generic crater models provided by geologists and geophysicists as closely as possible. 

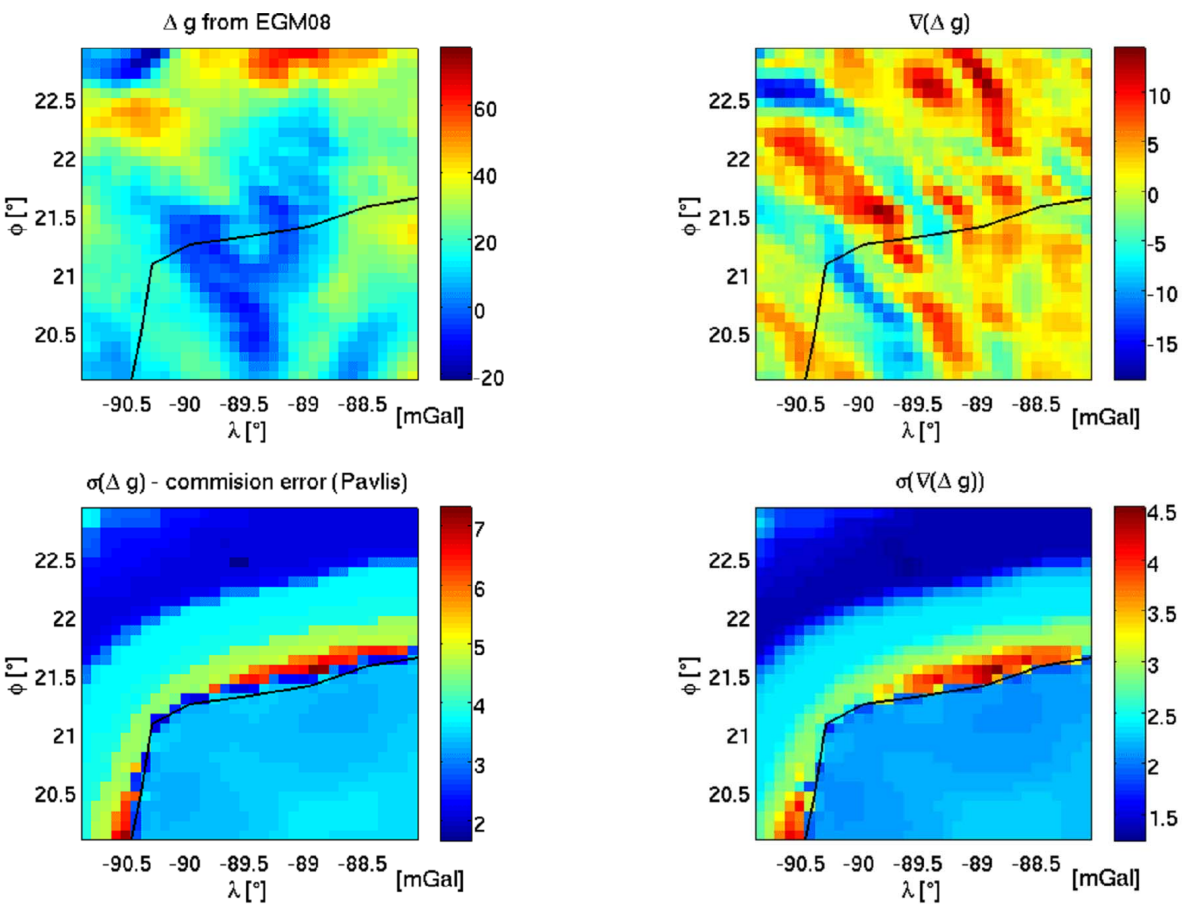

(a)
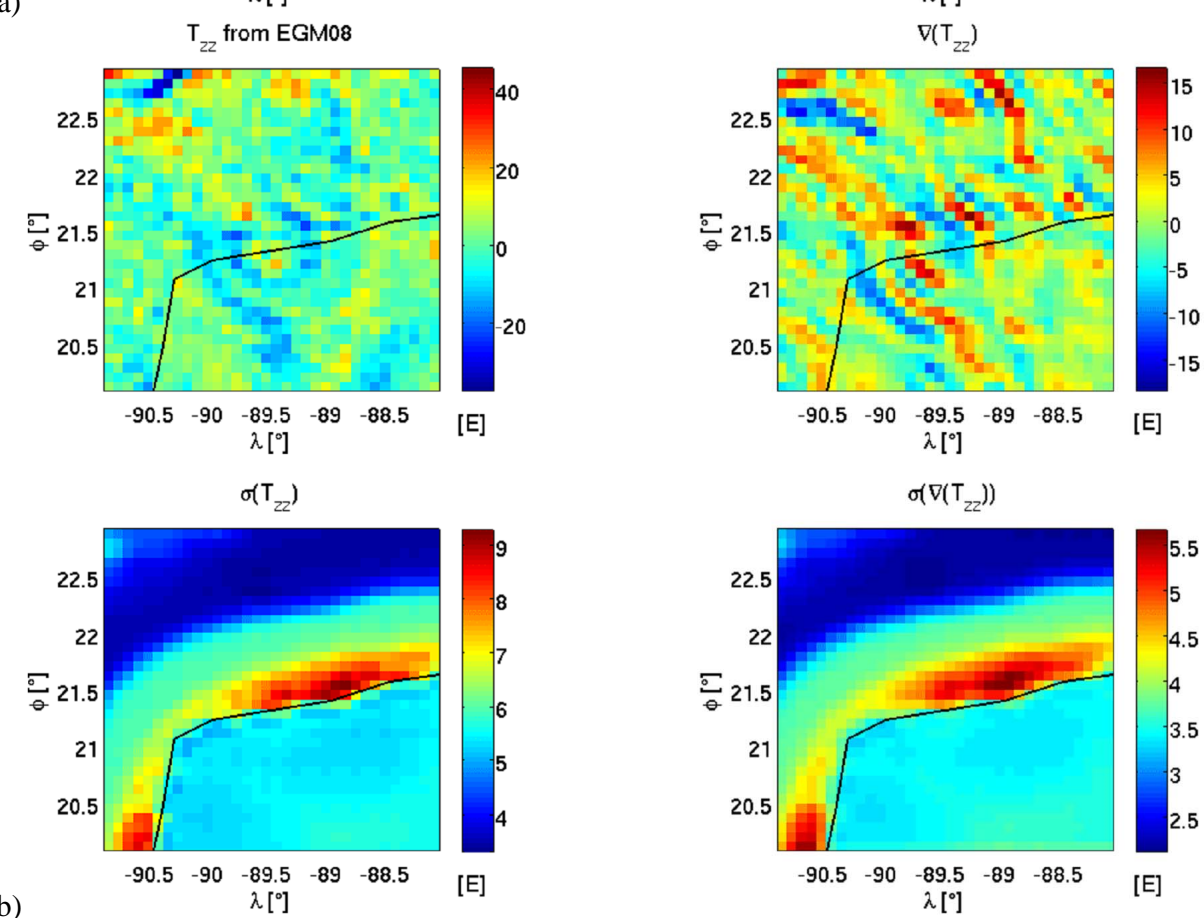

Fig. 8. (a): Comparison of the gravity anomaly $\Delta g$ (upper left) and its gradient (upper right) with relevant $\sigma(\Delta g)$ (lower left) and $\sigma(\operatorname{grad}(\Delta g))$ (lower right) for Chicxulub. (b): Comparison of the second radial derivative $T_{\mathrm{rr}}$ (upper left) and its gradient (upper right) with relevant $\sigma\left(T_{\mathrm{rr}}\right)$ (lower left) and $\sigma\left(\operatorname{grad}\left(T_{\mathrm{rr}}\right)\right)$ (lower right) for Chicxulub.

\subsubsection{Tests of crater modeling}

First we modeled Clearwater Lake (Canada) and RiesSteinheim (Germany) known as double impact craters to learn from these examples how to do the modeling, which is an improperly posed inverse task. We have only limited geological information (shape of the crater and density contrasts) to define external constraints. The Clearwater Lake craters are supposed to have been created simultaneously by two impactors of a comparable size, while the size-difference 

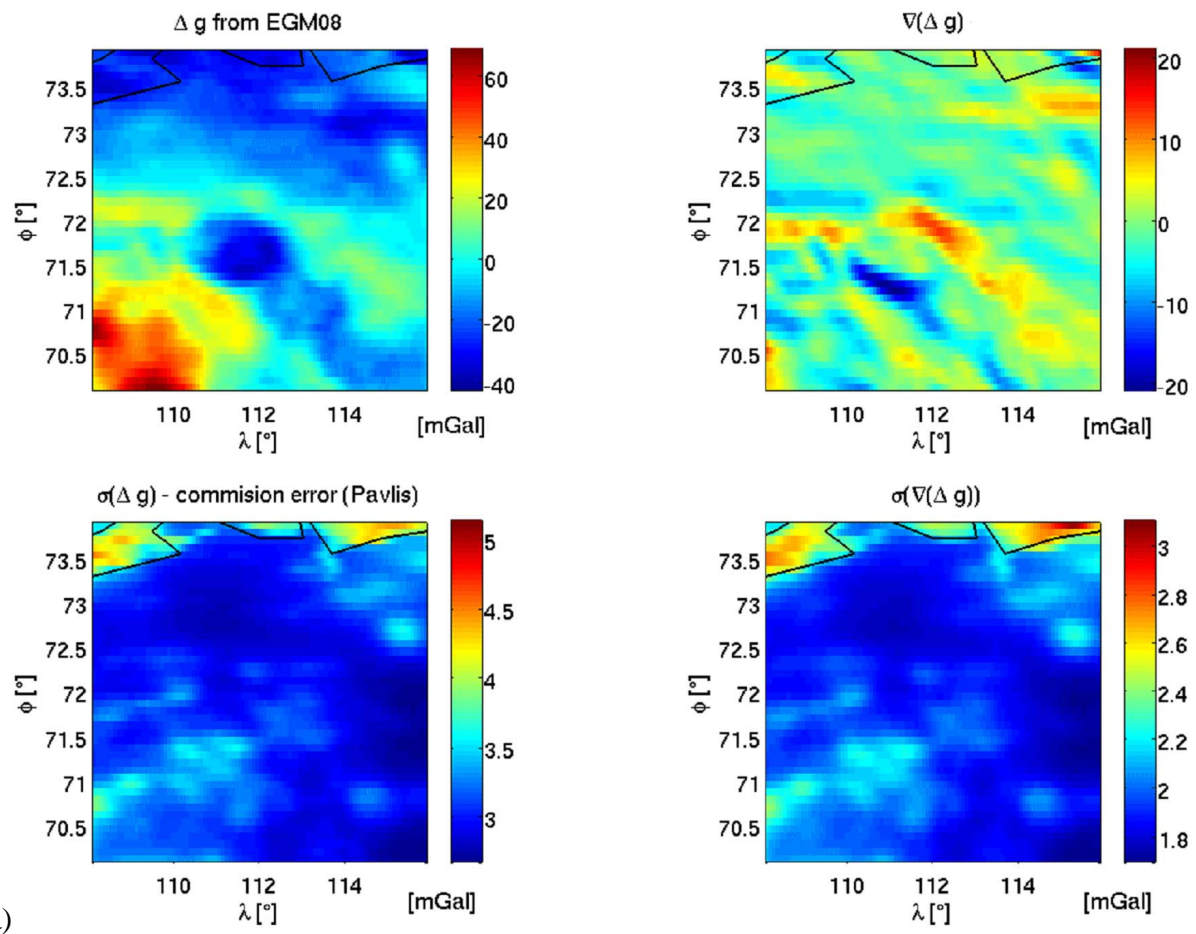

(a)

$\mathrm{T}_{\mathrm{zz}}$ from EGM08
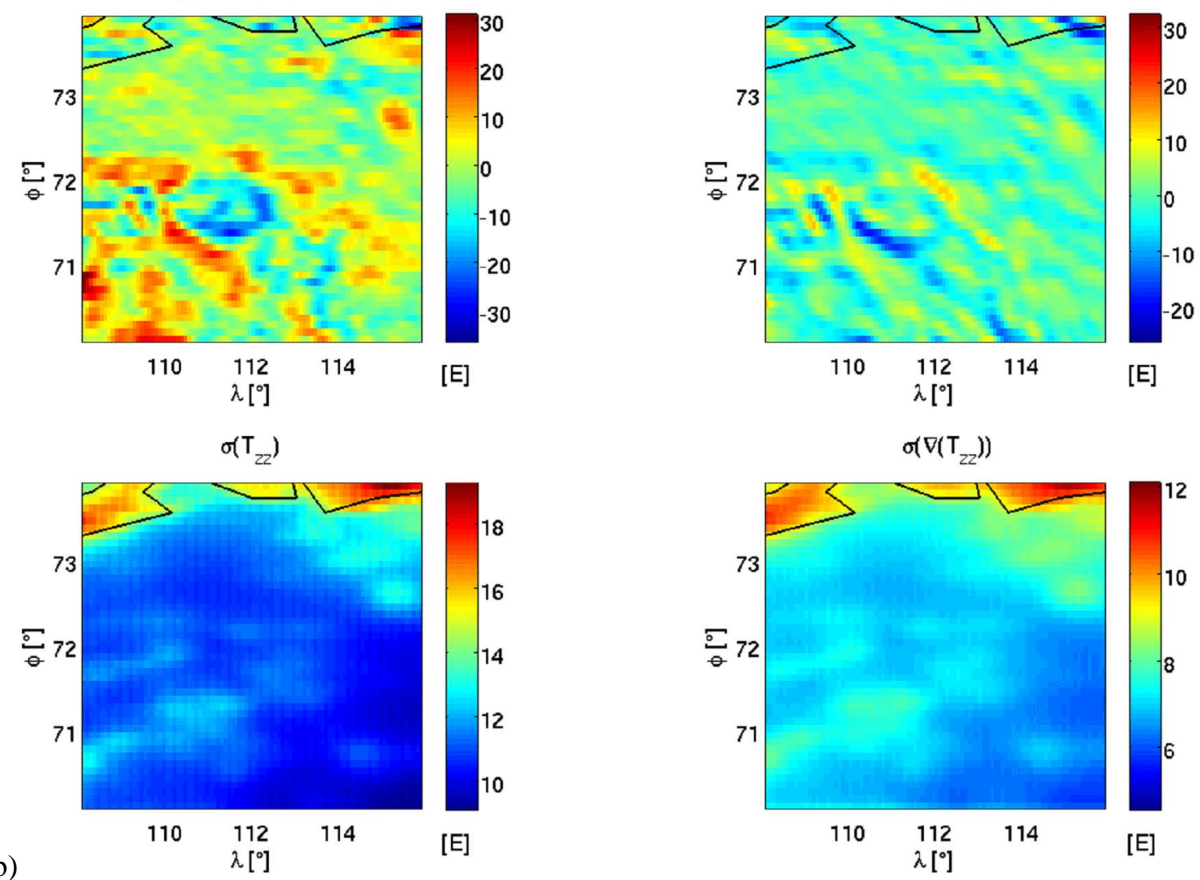

Fig. 9. (a): Comparison of the gravity anomaly $\Delta g$ (upper left) and its gradient (upper right) with relevant $\sigma(\Delta g)$ (lower left) and $\sigma(\operatorname{grad}(\Delta g))$ (lower right) for Popigai. (b): Comparison of the second radial derivative $T_{\mathrm{rr}}$ (upper left) and its gradient (upper right) with relevant $\sigma\left(T_{\mathrm{rr}}\right)$ (lower left)and $\sigma\left(\operatorname{grad}\left(T_{\mathrm{rr}}\right)\right)$ (lower right) for Popigai.

for Ries and Steinheim is large. The former can be detected as a double crater by EGM2008, the latter not.

Here we present an example for the Clearwater craters. The western and eastern craters differ substantially, both in the form and in the gravity anomalies (not in size). This is explained by the timing of the event. First the eastern crater was created in the granite rock. When the second impactor hit the ground, already affected (over a wide area) 
Table 3. Impactors and impacts.

\begin{tabular}{lrrrrrr}
\hline name of craters & \multicolumn{2}{c}{ diameters of craters } & \multicolumn{2}{c}{ diameters of impactors } & \multicolumn{2}{c}{$a / \mathrm{D}_{1}$} \\
& $d_{1}[\mathrm{~km}]$ & $d_{2}[\mathrm{~km}]$ & $a[\mathrm{~km}]$ & $D_{1}[\mathrm{~km}]$ & $D_{2}[\mathrm{~km}]$ & \\
\hline Clearwater & 36 & 26 & 31 & $2-3$ & 0.7 & $10-16$ \\
Lakes & & & & & & \\
Ries Steinheim & 24 & 4 & $40-50$ & $2-3$ & $?$ & $>10$ \\
Chicxulub I, II & 170 & $60-80$ & 100 & $10 ?$ & $?$ & $10 ?$ \\
Popigai I, II & 100 & 80 & $100-120$ & $10 ?$ & $?$ & $10-12 ?$ \\
\hline
\end{tabular}

$a=$ distance between geometric centers of the craters

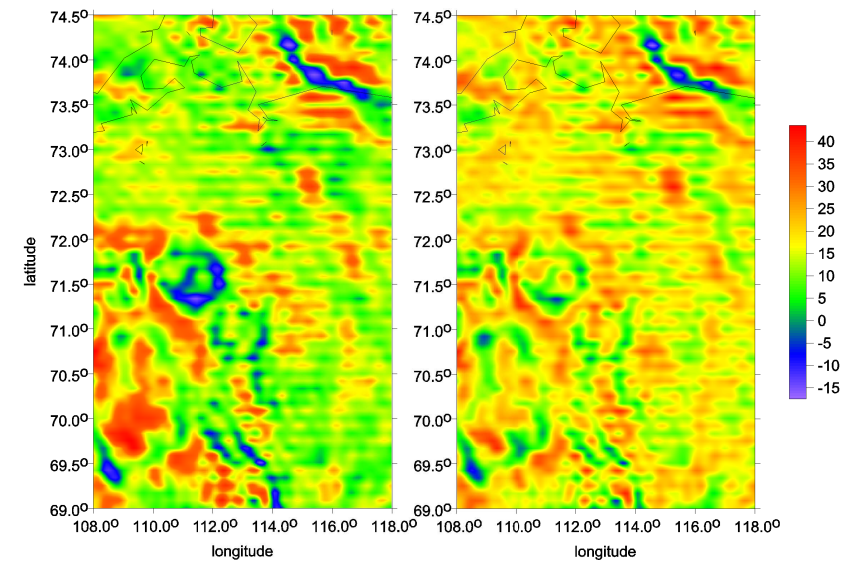

Fig. 10. (a)-(b): The second radial derivatives $[E]$ without the low or lower portion of the harmonic coefficients - panel (a) (left) without those coefficients to degree and order 36, panel (b) (right) without those to degree and order 360, based on EGM2008.

by the first hit, the shocked granite responded like dry sandstone (Hische, 1994). Using Hische's profile, density defects $\left(-0.07 \mathrm{~kg} / \mathrm{m}^{3}\right.$ for the western crater and $-0.40 \mathrm{~kg} / \mathrm{m}^{3}$ for the eastern crater), and depth $\sim 2 \mathrm{~km}$, our model yields gravity anomalies as shown in Fig. 11a and the second radial derivatives, Fig. $11 \mathrm{~b}$. There is a very good agreement between the masses-model and EGM2008.

\subsubsection{Modeling of Popigai and Chixculub}

The EGM2008 survey of Popigai shows a series of circular features in addition to the "primary" crater. Of them the nearest one is strongest and shows a structure very similar to the "primary". This similarity indicates that, if Popigai is a multiple crater, the system may have been created simultaneously.

Our model of Popigai is based on the Pilkington's et al. (2002) final crater profile. The diameter is taken as $100 \mathrm{~km}$, depth $6 \mathrm{~km}$, the density varies from $-0.07 \mathrm{~kg} / \mathrm{m}^{3}$ at the bottom to $-0.22 \mathrm{~kg} / \mathrm{m}^{3}$ at the top, and is slightly inclined from NW to SE. The computed companion is located $95 \mathrm{~km}$ SE from the center of the "primary" crater, with the diameter $\sim 80 \mathrm{~km}$. We kept the same structure and density for this area as those of the "primary" crater. Only the depth was decreased to $2.5 \mathrm{~km}$ (experimentally). However, the modelled surface gravity anomalies as well as the second radial derivatives were too detailed to be suitable for a "ground" comparison with EGM2008. Thus, they were smoothed by recalculating them at altitude $1.5 \mathrm{~km}$ to get the resolution corresponding to that of the EGM2008. The results are presented in Fig. 12a and b.

The model of Chicxulub is based on the Surendra (2004) seismic model, and anomalies are taken from Sharpton et al. (1994) and from EGM2008. Its diameter is about $170 \mathrm{~km}$ and depth $8 \mathrm{~km}$. It is buried $2 \mathrm{~km}$ beneath the present-day surface. Terraces are modelled by a blunted cone, $80 \mathrm{~km}$ in diameter at the bottom and $180 \mathrm{~km}$ on its top. Central uplift is represented by a cylinder $50 \mathrm{~km}$ in diameter. The density defects are $+0.10 \mathrm{~kg} / \mathrm{m}^{3}$ for both the terraces and uplift, $-0.15 \mathrm{~kg} / \mathrm{m}^{3}$ for the rest of crater filling, and $-0.25 \mathrm{~kg} / \mathrm{m}^{3}$ for the sedimentary cover.

The computed companion of Chicxulub is smaller than the "primary" crater, some $60 \mathrm{~km}$ in diameter, and is located $\sim 85 \mathrm{~km}$ NE from the center of the "primary" crater. Retaining the same structure, its depth is set to $4 \mathrm{~km}$, sedimentary cover to $1 \mathrm{~km}$, the terrace cone $35-60 \mathrm{~km}$ and the uplift diameter $20 \mathrm{~km}$. The model yields gravity anomalies and the second radial derivatives as shown in Fig. 13a and b.

\subsection{Notes from astronomy}

A fraction of binary systems in the population of near-Earth asteroids is $15 \pm 4 \%$ (e.g., Pravec et al., 2006). Most binary asteroids are, however, close systems with separations of components so small (see Pravec and Harris, 2007) that they produce typically a single crater when they impact the Earth. A terrestrial impact record of binary asteroids is therefore scarce, with only three double craters identified so far (see Melosh and Stansberry, 1991; Bottke and Melosh, 1996); they could be produced by impacts of less common wide binary systems that are observed in the binary population with a lower frequency.

Table 3 shows some parameters of the binary asteroids (potential impactors) and the impact craters together. For 


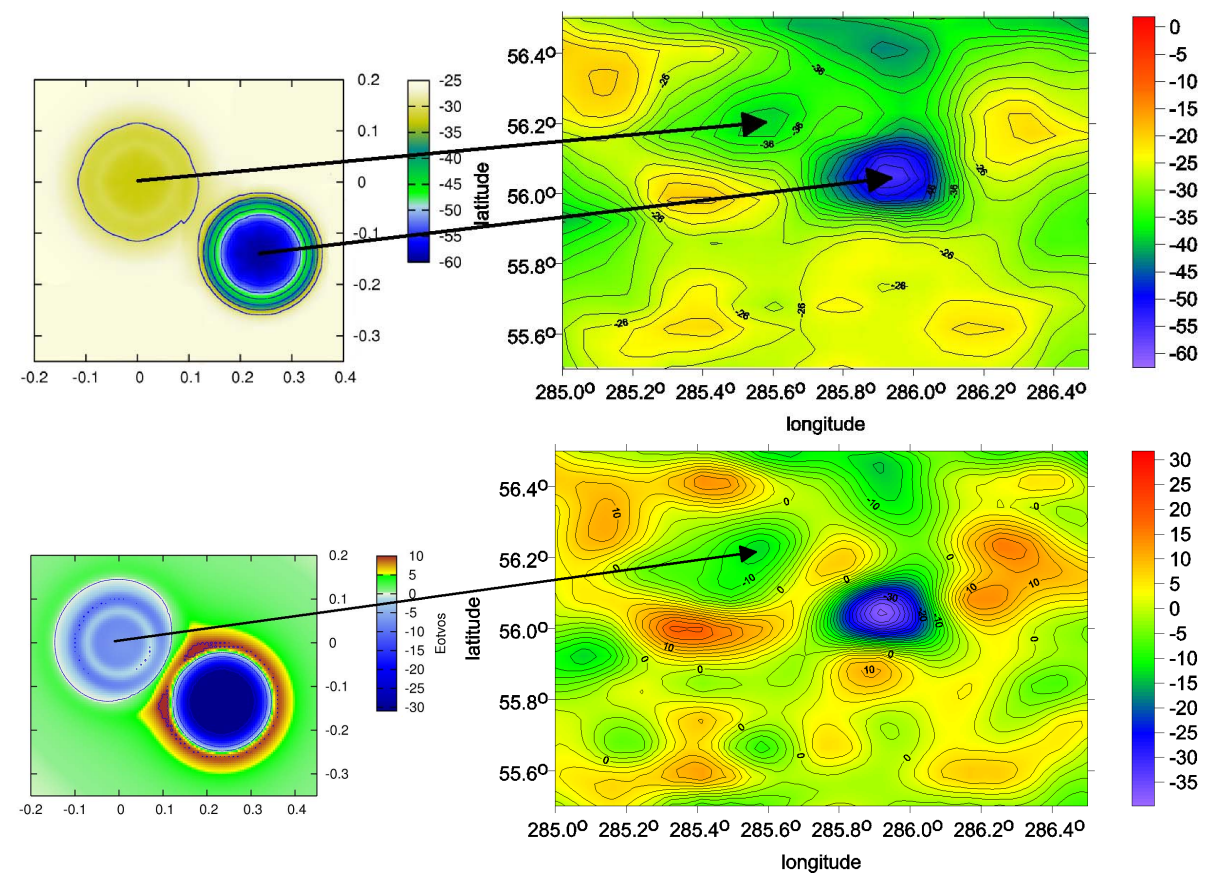

Fig. 11. (a): Gravity anomalies of the Clearwater double crater (in mGal) as derived from the crater model (upper left). Agreement with EGM2008 anomalies (upper right) is clearly seen. Coordinate axes, $x$ for $\lambda \cos \varphi$ and $y$ for $\varphi$ are in degrees. (b): The second radial derivatives of potential, $T_{\mathrm{rr}}$, of the Clearwater double structure (in E) as derived from the model (bottom left) and EGM2008 (bottom right).

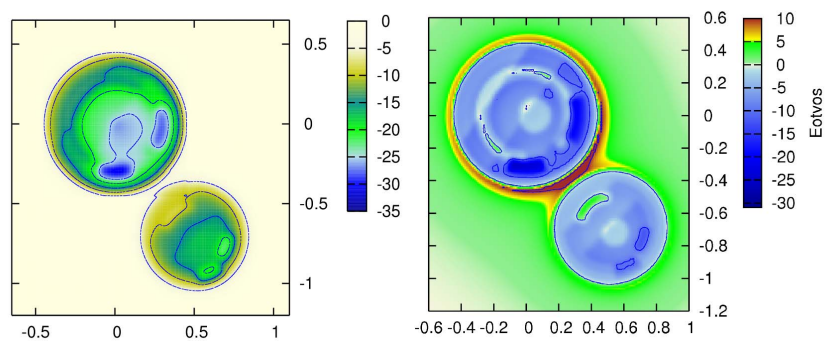

Fig. 12. (a)-(b) Gravity anomalies (left) and the second radial derivatives, $T_{\mathrm{rr}}$, (right), of Popigai and its possible nearest companion (in $\mathrm{mGal}$ and $\mathrm{E}$, respectively) as derived from the craters model. To be comparable with EGM2008 (see Figs. 2 and 3), the models were smoothed to the EGM2008 resolution. Coordinate axes, $\lambda \cos \varphi$ and $\varphi$ are in degrees.

ordinary close and stable binary asteroids the ratio $a / D_{1}$ is typically 3 (the symbols are explained at Table 3 ). But proved double craters on the Earth (Clearwater Lakes and RiesSteinheim) have $a / D_{1} \sim 10$. Relevant systems of the binary asteroids are also known, but they are not frequent (Pravec and Harris, 2007), because their lifetime is short; thus there is an evolutionary selection effect. For our new candidates for the double/multiple craters, we have $a / D_{1} \sim 10$, too. With the help of Pravec and Harris, (2007) and other information (e.g., Pravec, private communication, 2009) we see that astronomers do not exclude the existence of such asteroids

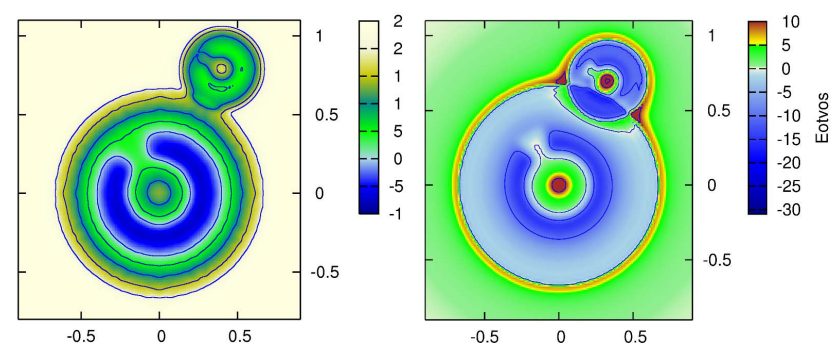

Fig. 13. (a)-(b) Gravity anomalies (left) and the second radial derivatives, $T_{\mathrm{rr}}$ (right), of Chicxulub and its hypothetic companion (in $\mathrm{mGal}$ and $\mathrm{E}$, respectively) as derived from the craters model. For EGM2008 see Figs. 4 and 5.

which we could use to create our candidates for possible double/multiple impact structures such as at Chicxulub or Popigai.

\section{Testing the predicted second impact crater at Chicxulub with seismic data}

Although all our tests indicate a second impact crater at Chicxulub, we know the gravity data alone is not definitive. There are good examples of how the gravity information alone may be misleading: Hudson Bay shows well defined circular like features namely in the second derivatives while 
geologists know that there is no impact crater there. On the contrary the Alamo crater in the USA is an impact crater but without any obvious circular like gravity signature.

During the review of this manuscript, we were made aware of multi-channel seismic data, a seismic velocity model, and their interpretations (Christeson, 2010), which indicate this area is a relatively undisturbed sedimentary basin. Christeson recalled existing seismic profiles from the recent literature on Chicxulub (Gulick et al., 2008; Christeson et al., 2009) which we unfortunately did not know. She wrote:... "These data show no evidence for a secondary crater (at Chixculub).... a more likely explanation for the perturbation in the gravity field is that it is associated with a pre-existing Crateceous basin proposed for this location (Gulick et al., 2008)". Why this basin is so circular in the gravity data is still a mystery. This finding demonstrates the importance of obtaining all available geological data, including new data to test the results of analyses from gravity-only information. At Popigai we have no other data to support alternative explanation of what appears to be a "chain" of impact craters similar to the known "primary".

\section{Conclusions}

Using selected functionals of the disturbing potential (mainly the gravity anomaly and second radial derivative, Sect. 2.2), computed from the recent, high resolution Earth Gravitational Model (EGM2008) provided in a spherical harmonic expansion, we have confirmed the existence of circular or circular-like geopotential structures at nearly all existing larger well known impact craters (with diameter $>30 \mathrm{~km}$ ). This is a useful test of the model EGM2008.

However, the most interesting inference from this survey and subsequent analysis is the likelihood that at least two of the well known crater sites originally thought to be single may be double or multiple impact craters (Chicxulub and Popigai), Sect. 3. We gathered support for this conclusion (Sect. 4). However, the gravity data alone never provides a unique result for an underlying structure. In the case of Chicxulub, Christeson (2010 and references therein) claim that this area is likely to be a pre-existing basin (Sect. 5). Popigai crater still appears to be a multiple impact crater from the evidence of EGM2008.

Acknowledgements. This research was supported by the ESA PECS grant C 98056. We are grateful to Jianliang Huang and Nikolaos K. Pavlis from the IAG Evaluation team for the EGM2008 harmonic geopotential coefficients and various consultations. We also thank our colleagues Mark Pilkington, David Vokrouhlický, Václav Cílek, David Rajmon, Gunter Kletetschka, Petr Pravec, and Ivanka Charvátová for fruitful discussions and to our referees D. Chambers and Ch. Foerste, Ms. G. Christeson for her SED contribution, and the Editor of SED/SE D. F. Naar.

Edited by: D. Naar

\section{References}

Andersen, O. B., Knudsen, P., Berry, P., and Kenyon, S.: The DNSC08 ocean wide altimetry derived gravity field, Presented EGU-2008, Vienna, Austria, 2008.

Bottke, W. F., Vokrouhlický, D., and Nesvorný, D.: An asteroid breakup $160 \mathrm{Myr}$ ago as the probable source of the K/T impactor, Nature, 449, 48-53, 2007.

Bottke, W. F. and Melosh, H. J.: Formation of asteroid satellites and doublet craters by planetary tidal forces, Nature, 381(6577), 51-53, 1996.

Christeson, G. L., Collins, G. S., Morgan, J. V., Gulick, S. P. S., Barton, P. J., and Warner M. R.: Mantle deformation beneath the Chicxulub impact crater, Earth Planet. Sc. Lett., 284, 249-257, doi:10.1016/j.epsl.2009.04.033, 2009.

Christeson, G. L.: Interactive comment on Candidates for multiple impact craters: Popigai and Chicxulub as seen by EGM08, a global $5^{\prime} \times 5^{\prime}$ gravitational model by J. Klokočník et al., Solid Earth Discuss., 2, C21-C24, 2010.

Elkins, T. A.: The second derivative method of gravity interpretation, Geophysics, 16, 29-50, 1951.

Espindola, J. M., Mena, M., de La Fuente, M., and CamposEnriquez, J. O.: A model of the Chicxulub impact structure (Yucatan, Mexico) based on its gravity and magnetic signatures, Phys. Earth Planet. Int., 92, 271-278, 1995.

Evjen, H. A.: The place of the vertical gradient in gravitational interpretation, Geophysics, 1, 127-136, 1936.

French, B. M. and Koeberl, C.: The convincing identification of terrestrial meteorite impact structures: what works, what doesn't, and why, Earth Sci. Rev., 98(1-2), 23-170, 2010.

Gulick, S. P. S., Barton, P. J., Christeson, G. L., Morgan, J. V., McDonald, M., Mendoza-Cervantes, K., Pearson, Z. F., Surendra, A., Urrutia-Fucugauchi, J., Vermeesch, P. M., and Warner, M. R.: Importance of pre-impact crustal structure for the asymmetry of the Chicxulub impact crater, Nat. Geosci., 1, 131-135, doi:10.1038/ngeo103, 2008,

Hildebrand, A. R., Pilkington, M., Connors, M., Ortiz-Aleman, C., and Chavez, R. E.: Size and structure of the Chicxulub crater revealed by horizontal gravity gradients and cenotes, Nature, 376, 415-417, 1995.

Hildebrand, A. R, Pilkington, M., Ortiz-Aleman, C., Chavez, R. E., Urrutia-Fucugauchi, J., Connors, M., Graniel-Castro, M., Camara-Zi, A., Halpenny, J. F., and Niehaus, D.: Mapping Chicxulub crater structure with gravity and seismic reflection data, in: Meteorites: Flux with Time and Impact Effects, edited by: Grady, M. M., Hutchinson, R., McCall, G. J. H., and Rothey, D. A., Geolog. Soc. London, Spec. Publs, 140, 177-193, 1998.

Hildebrand, A. R., Millar, J. D., Pilkington, M., and Lawton, D. C.: Chicxulub crater structure revealed by three dimensional gravity field modeling, in Large Meteorite Impacts, 3rd Int. Conf. On Large Meteorite Impacts, Nordlingen, Germany, 2003.

Hische, R.: Clearwater impact structure, Quebec, Canada: Modeling of the impact conditions, Meteoritics, 29, 473-474, 1994.

Hofmann-Wellenhof, B. and Moritz, H.: Physical geodesy, Second edition, Springer-Verlag, ISBN:3-211-33544-7, 2006.

Holmes, S. A., Pavlis, N. K., Novák, P., et al.: A fortran program for very-high degree harmonic synthesis, version 05/01/2006, 2006.

Klokočník, J., Bezděk A., Gruber, Ch., Kostelecký, J., Novák, P., Pešek, I., Vondrák, J.: GOCE - specific tasks on fine gravity field structure of the Earth, Report for ESA, Astronom. Inst. Czech 
Acad. Sci., Ondřejov, 2008a.

Klokočník, J., Novák, P., Pešek, I., Kostelecký, J. and Wagner, C. A.: EGM2008: Tests of the model and simulations for GOCE, presented at IAG Interntl. Symp. GGEO 2008, Chania, Greece, June, 2008b.

Lemoine, F., Kenyon, S. C., Factor, J. K., Trimmer, R. G., Pavlis, N. K., Chinn, D. S., Cox, C. M., Klosko, S. M., Luthcke, S. B., Torrence, M. H., Wang, Y. M., Williamson, R. G., Pavlis, E. C., Rapp, R. H., and Olson, T. R.: The development of the joint NASA GSFC and the NIMA geopotential model EGM96, NASA/TP-1998-206861, NASA GSFC Greenbelt, 1998.

Masaitis, V. L.: Popigai crater: Origin and distribution of diamondbearing impactites, Meteoritics, 33, 349-359, 2005.

Masaitis, V. L., Naumov, V. M., and Marschak, M. S.: Original diameter and depth of erosion of the Popigai impact crater, Russia. Geolog. Soc. Amer., Special paper 354, in Large meteorite impacts III, edited by: Kenkmann, T., Horz, F., and Deutsch, A., 131-140, 2005

Melosh, H. J. and Stansberry, J. A.: Doublet craters and the tidal disruption of binary asteroids, Icarus, 94(1), 171-179, 1991.

Moritz, H.: Geodetic Reference System 1980, Bulletin Geodesique, 58, 388-398, 1984.

Pavlis, N. K, Holmes, S. A., Kenyon, S. C., and Factor, J. K.: An Earth Gravitational Model to degree 2160: EGM 2008, presented at session G3: "GRACE Science Applications", EGU Vienna, April, 2008
Pavlis, N. K., Holmes, S. A., Kenyon, S. C., and Factor, J. K.: EGM 2008: An overview of its development and evaluation. Presented at IAG Int. Symp. GGEO 2008, Chania, Greece, June, 2008.

Pavlis, N. K. and Saleh, J.: Error Propagation with Geographic Specificity for Very High Degree Geopotential Models, Gravity, Geoid and Space Missions, Springer Berlin Heidelberg, 2005.

Pilkington, M. and Grieve, R. A. F.: The Geophysical Signature of Terrestrial Impact Craters, Rev. Geophys., 30, 161-181, 1992.

Pilkington, M., Pesonen, L. J., Grieve, R. A. F., and Masaitis, V. L.: Geophysics and Petrophysics of the Popigai Impact Structure, Siberia; in: Impacts in Precambrian Shields, edited by: Plado, J. and Pesonen, L. J., Springer-Verlag, 87-107, 2002.

Pravec, P., Scheirich, P., Kušnirák, P., and 54 others: Photometric survey of binary near-Earth asteroids, Icarus, 181, 63-93, 2006.

Pravec, P. and Harris, A. W.: Binary asteroid population, 1. Angular momentum content, Icarus, 190, 250-259, 2007.

Rajmon, D.: Impact database 2009, v. 2010.1,http://impacts. rajmon.cz, last access: 16 July 2010.

Sharpton, V. L., Burke, K., Camargo-Zanoguera, A., Hall, S. A., Lee, D. S., Marin, L. E., Suarez-Reynoso, G., Quezada-Muneton, J. M., Spudis, P. D., and Urrutia-Fucugauchi, J.: Chicxulub multiring impact basin: size and other characteristics derived from gravity analysis, Science, 261, 1564-1567, 1993.

Surendra, A.: 3D tomographic imaging of the Chicxulub impact crater, Lithos Science Report, 6, 89-92, 2004.

Vermeesch, P. and Morgan, J. V.: Structural uplift beneath the Chicxulub impact structure, J. Geophys. Res., 113, B07103, doi:10.1029/2007/JB005393, 2008. 